\title{
A ADMINISTRAÇÃO DAS ÁREAS VERDES PÚBLICAS E ESPAÇOS LIVRES NAS CIDADES ALEMÃS
}

\author{
Heiner Baumgarten ${ }^{1}$
}

\section{Tradução de Paulo Celso Dornelles Del Picchia²}

As áreas verdes de uma cidade determinam o caráter de uma paisagem urbana e influenciam a qualidade de habitação, trabalho e vida das pessoas. Na Alemanha, por exemplo, as empresas tomam suas decisões de localização levando em conta a oferta de áreas verdes para o tempo livre e lazer e o ramo imobiliário desenvolve seus preços de terrenos e alugueis apreciando a distribuição das áreas verdes de uma cidade. Sob este aspecto as tarefas das repartições de parques e jardins na Alemanha hoje têm não só um significado plástico, ecológico e social, mas também, um não subestimável significado econômico.

\section{TAREFAS DA ADMINISTRAÇÃO DAS ÁREAS VERDES}

O espectro de tarefas das repartições de áreas verdes urbanas não é homogêneo. A organização das tarefas e administração nas cidades ajusta-se fundamentalmente ao modelo da Repartição Municipal para Simplificação Administrativa (KGSt), permanecendo porém finalmente na consideração e poder de decisão de cada municipalidade. Uma cidade hoje ainda mal manteve uma estrutura administrativa desenvolvida pela KGSt: novas tarefas como a Proteção ao Meio Ambiente ou outras prioridades políticas estabelecidas levaram a novas estruturas organizativas. Tradicionalmente as repartições de áreas verdes pertencem como "Repartições de Horticultura" às repartições de obras das cidades e municípios. Hoje, freqüentemente, por motivo de uma mudança de espectro de tarefas estão submetidas às repartições de meio ambiente. Em algumas cidades as repartições de áreas verdes por si só desenvolveram-se em repartições ambientais e assumiram não só tarefas das áreas verdes públicas e no campo da proteção à natureza, porém, respondem por questões de manutenção dos cursos d'água ou da proteção do solo.

A GALK como organização alemã de cupola serve essas repartições na colocação de diferentes tarefas, porém tendo como tarefa central o "verde e a proteção à natureza" e constitui um importante vinculo de conteúdo e organização no parlamento das cidades

\footnotetext{
${ }^{1}$ Presidente da Conferencia Permanente dos Diretores de parques e Jardins do Parlamento das Cidades Alemãs (GALK-DST), Hamburgo

${ }^{2}$ Arquiteto, Mestre em Estruturas Ambientais Urbanas, FAU - USP, Presidente da SBAU na diretoria 2004/2005, delpaulo@ajato.com.br
} 
alemãs e, também, um fórum especializado para a troca de informações. Por isso, na GALK estão representados todos os escritórios de serviço das cidades, os quais são responsáveis pela "tarefa verde".

\section{TAREFAS NA PASSAGEM DOS ÚLTIMOS CINQÜENTA ANOS}

Há cinqüenta anos atrás estavam as cidades alemãs no centro da fase de reconstrução depois da Segunda Guerra Mundial e precisaram da competência dos jardineiros para a configuração da cidade e o restabelecimento de uma qualidade de vida e de moradia. Ao lado do planejamento e da construção de novas áreas verdes juntamente com a construção de novas habitações e ampliação da cidade necessitou-se do restabelecimento de inúmeros parques tornando-os acessíveis ao lazer da população. Em Hamburgo, entre outros, o Parque da Cidade que durante os últimos anos de guerra e nos primeiros anos após foi convertido sob o domínio da grande necessidade em parte como área de sepultamento e suas árvores foram transformadas em lenha para o aquecimento da população.

As "Repartições de Jardins e Cemitérios", como a maioria das cidades naquele tempo designavam suas unidades administrativas de áreas verdes, com sua ação conjunta na reconstrução no tempo do boom de obras dos anos sessenta e setenta, e durante a fase subseqüente na crítica discussão do desenvolvimento urbano e na gênese da moderna legislação de proteção à natureza adquiriram uma posição forte dentro das administrações urbanas. As repartições de áreas verdes transformaram-se graças a sua grande atuação em repartições de planejamento. Elas tiveram em mãos com a nova legislação de proteção à natureza no meio dos anos setenta o correspondente instrumento do planejamento da paisagem e foram adicionalmente fortalecidas em sua competência pela regulamentação da Lei de Proteção à Natureza, de modo que para cada perda de áreas verdes e áreas naturais uma compensação deve ser feita. As novas tarefas e competências levaram também, conseqüentemente, a alterações na denominação das repartições: "Repartição para a Conservação da Paisagem e Áreas Verdes", "Repartição para a Proteção à Natureza e ao Verde" ou, simplesmente, "Repartição das Áreas Verdes". Isto documenta o crescimento dessas tarefas e competências.

As repartições de áreas verdes foram levadas a sério como parceiras - do ponto de vista de muitos planejadores urbanos também como concorrentes - no planejamento e desenvolvimento urbano. Um planejamento da paisagem ativo e consciente encontrou nos anos 1980 uma população sensibilizada pelas questões ambientais, fortalecendo as repartições ainda mais. O paralelismo concorrente de planejamento urbano e da paisagem bem como o crescente déficit orçamentário logo levaram às primeiras reflexões sobre uma 
modernização administrativa. Muitas cidades incumbiram conselheiros empresariais de elaborar propostas para esse processo e curvaram-se progressivamente ao fomento da economia privatizando funções da cidade. Nessa discussão ficaram também as repartições de áreas verdes no ponto central: as questões "Pode o planejamento, construção e manutenção das áreas verdes ser privatizados?" e "Pode-se planejamento urbano e da paisagem por motivo de maior eficiência ser organizados conjuntamente?" entrou na substância e existência das repartições autônomas.

Assim, muitas cidades hoje passaram a fundar esses conhecidos serviços autônomos estes são serviços urbanos estruturados como empresas privadas -, através do enfeixamento de tarefas de planejamento ou através da privatização de funções compartilhando as tarefas gerais das repartições de áreas verdes. A Conferencia Alemã dos Diretores de Repartições de Jardins do Parlamento das Cidades Alemãs (GALK-DST) criticou asperamente essa evolução e tomou posição contra esse desenvolvimento. Em algumas cidades estão sendo conhecidos expressamente os inconvenientes desse estilhaçamento das competências e começou novamente uma sucessiva volta a estruturas comprovadas. Esperar somente por essa volta e com isso poder assegurar a qualidade das áreas verdes urbanas não é suficiente, pois as cidades alemãs estão diante de novas difíceis tarefas. Uma atividade central da GALK é, talvez, no momento, definir as tarefas futuras para as cidades e, com isso, definir novamente, também, as Repartições de Áreas Verdes.

\section{O FUTURO DAS REPARTIÇÕES DE ÁREAS VERDES}

$\mathrm{Na}$ Alemanha em quase todas as cidades diminui o número de habitantes continuamente. A maioria das pessoas aspiram por uma casa no verde e mudam-se para as áreas rurais na periferia urbana. Além do que na Alemanha situa-se o quociente de mortes mais alto do que o de nascimentos: também esta tendência é maior nas cidades do que nas áreas rurais. A imigração de estrangeiros não compensa atualmente o natural retrocesso populacional.

Paralelamente a esse desenvolvimento populacional muitos usos do solo nas cidades foram abandonados: praças de manobras militares e quartéis, velhas instalações de estradas de ferro, antigas instalações industriais (p. ex. mineração) ou recentemente também grandes edifícios administrativos de conglomerados internacionais que unificam suas sedes nacionais e internacionais.

Dessa forma apresenta-se para as repartições de áreas verdes na Alemanha novos princípios para trabalhar, os quais devem ser discutidos na política com os cidadãos veementemente. 
Depende de qualificar a função das repartições de áreas verdes na nova fase do desenvolvimento urbano e para a qualidade de vida da cidade. Para tanto são apontados exemplarmente alguns complexos temas.

\section{MUDANÇA NO USO DO SOLO}

Nossas cidades alemãs encontram-se em mudança. Extensas áreas após uma longa década mudam de uso e colocam a Administração e a Política diante de questões e problemas completamente novos de planejamento no futuro. Nas cidades alemãs do leste grandes áreas habitadas sofreram êxodos dramáticos e a tendência de longa data de obter a casa própria foi abandonada e, finalmente, as construções aí foram demolidas. Na Alemanha ocidental foram, também, progressivamente abandonadas áreas por processos de racionalização e fusão de empresas juntamente com antigas áreas de uso militar e de ferrovias: grandes corporações reúnem suas áreas administrativas e as modernizam e assim, "cidades de escritórios" ficam desertas. A internacionalização e a introdução de novas tecnologias de comunicação no futuro provocará a mudança de uso de muitas áreas em nossas cidades.

As conseqüências dessa situação é o aumento das áreas urbanas públicas e privadas abandonadas nas cidades alemãs e a impossibilidade de que a curto prazo elas venham a ter um novo uso e isto prejudica significativamente a paisagem urbana, porém, essas áreas constituem um potencial para o desenvolvimento ecológico e de planejamento de áreas verdes.

As repartições de áreas verdes precisam colocar-se nesse processo e ativamente plasmar essas áreas em mudança de uso. Terrenos que estão se tornando livres não devem cunhar como áreas desoladas por meses ou anos a paisagem urbana, prejudicar sua atratividade e, como conseqüência, levar a desenvolvimentos negativos como o êxodo dos moradores para fora dos bairros urbanos afetados.

"Plasmar a mudança" significa reconhecer tendências e desenvolvimentos e prover com novas metas as mudanças que se esboçam na cidade. Justamente nas diversas cidades da Alemanha oriental onde inteiras áreas urbanizadas na forma de construção extensiva destroem o solo é que faltam freqüentemente novas perspectivas. As áreas modificadas produzem uma sensação vazia e deprimente, elas despertam pouca esperança de um desenvolvimento urbano ativo e criativo no futuro.

Uma possível alternativa a essa situação é o prematuro novo projeto das áreas tendo em vista uma desejável situação urbanística. As áreas verdes e as estruturas verdes nas áreas de desenvolvimento urbano e de expansão urbana são conseguidas no caso primeiramente com ou depois do acabamento da estrutura da obra, assim ocorre 
razoavelmente em espaços que estão se tornando baldios (industria, escritórios, residências, agricultura, instalações militares e ferroviárias, etc.) uma conformação efetuada com verde que consegue uma qualidade, uma atmosfera e uma atratividade que procuram e necessitam a administração residencial e a empresa industrial. Muitos exemplos na Alemanha provam que empresas ao escolher suas localizações são atraídas pela atratividade dos setores urbanos ou da cidade onde a conformação e função de lazer ou a flutuação dos habitantes em bairros com uma boa formação é baixa. Uma tarefa importante no desenvolvimento urbano dos próximos vinte anos é, talvez, projetar conceitos de desenvolvimento para o "uso baldio" e a oportunidade de utilizar assim a qualidade de vida nas cidades através da conquista do melhoramento de novas áreas verdes.

As repartições de áreas verdes possuem para tais conceitos de desenvolvimento o necessário conhecimento especializado e a competência e podem conseguir estratégias para os "problemas setoriais urbanos" sob um ponto de vista ecológico e de projeto plástico bem como de um ponto de vista técnico. Elas estão na condição de unir a competência dos arquitetos paisagistas autônomos bem como das empresas de jardinagem e paisagismo de modo que para a cidade se desenvolva um resultado econômico ótimo. Projetos e planos para a conversão de sítios devem começar já antes da desocupação dos mesmos. A GALKDST deve dedicar-se com empenho nesse direcionamento do problema nos próximos anos.

\section{LAZER NA CIDADE}

Necessidades de recreação e lazer e de comportamento frente a recreação e lazer estão sujeitas a uma constante mudança e seguem freqüentemente tendências que são "conduzidas" pela industria do lazer ou pelos instauradores de modas. No lazer esportivo como o "joging", no ciclismo, voleibol de praia ou no skate procura-se lugares adequados nas áreas verdes urbanas, os quais satisfaçam a atividade corporal junto com a reivindicação social: "ser visto", "encontro de pessoas com os mesmos interesses", "ouvir música" ou simplesmente divertir-se. Todas as atividades necessitam além das áreas de ação, também dos pontos de encontro, os quais devem ser encontráveis na cidade dentro dos parques e das ligações verdes - ou justamente nas novas áreas baldias.

Em muitas cidades da Alemanha a estrutura de idades muda para uma dominância clara da geração acima dos sessenta anos. Como essa geração está provida de muito tempo livre e, igualmente, tem grande mobilidade, coloca-se a questão às repartições de áreas verdes de uma oferta de lazer para este grupo etário nas cidades. O banco de parque há muito tempo não é mais suficiente, os "jovens e os velhos errantes" procuram também ofertas de atividades (Fitness na velhice), espetáculos e lugares atrativos que atendam seus interesses e que sejam encontráveis em sua área de moradia. 
Áreas verdes constituem progressivos lugares para espetáculos de toda sorte. Eram obrigatórios nos tradicionais parques públicos palcos ao ar livre para concertos ou teatro, porém a maioria dos parques não eram concebidos para espetáculos. Desde alguns anos houve um grande crescimento de espetáculos nas áreas verdes. Assim, em Hamburgo, por exemplo, encontra-se festas de bairro, festas infantis, exposições de esculturas e eventos artísticos, feiras de plantas e espetáculos de lazer em todos os parques. Entretanto acontecem até mesmo comemorações de núpcias, festas de empresas ou festas de jubileu e de aniversário de particulares ou firmas nos parques.

Estes exemplos mostram que o significado e a função das áreas verdes na cidade mudam constantemente. Repartições de áreas verde, implementando conceitos, agindo preventivamente e em diálogo com os cidadãos, bem como com os empresários do ramo do lazer devem controlar as ofertas de áreas verdes considerando a importância dos aspectos de conformação, históricos e ecológicos. Hamburgo desenvolve nesse sentido um "Plano Especializado de Tempo Livre e Recreio" no âmbito da administração de áreas verdes e hoje oferece adequados espetáculos nos parques através da Internet (www.stadtgruen.hamburg.de).

Numa comparação de cidades do magazine FOCUS (1995) sob o título "Onde se vive melhor" ficou claro na questão "O que os alemães mais apreciam" que o campo de atuação das repartições de áreas verdes na avaliação está em alta:

- a paisagem da vizinhança $74 \%$

- áreas verdes urbanas e parques $70 \%$

- espaços urbanos centrais convidativos para compras e passeios $62 \%$

- centro velho com charme $46 \%$

- Rio/ lago com possibilidades de esporte aquático $41 \%$

- Barzinhos e cervejarias 39\%

- Áreas esportivas (esporte de base) $34 \%$

- Cinemas $22 \%$

- Instalações para esportes especiais (Pólo, Golf) 22\%

- Teatro e cena artística $18 \%$

As tarifas das repartições de áreas verdes tendo em vista essa escalação e as necessidades de lazer em constante mudança devem ser seguidamente repensadas. Essas exigências em constante mudança só podem ser cumpridas por repartições de áreas verdes qualificadas com competências abrangentes. 


\section{ESTRUTURAS ADMINISTRATIVAS MODERNAS ASSEGURAM QUALIDADE}

A estrutura administrativa que nos anos 1970 foi proposta como ótima para as repartições de áreas verdes nas cidades alemãs pela KGSt não corresponde hoje seguramente às modernas exigências. Fossem as tarefas então propostas suficientes nas tradicionais áreas de planejamento, obras e manutenção de parques, áreas de recreação, cemitérios, áreas esportivas, "kleingärten", etc., hoje a tarefa está mais concentrada na coordenação de questões ecológicas, sociais, técnicas e econômicas e influencia com ais força o planejamento, construção e manutenção das áreas verdes nas cidades.

Essa novas exigências incentivam novas qualificações entre os colegas das administrações de áreas verdes e, principalmente, dos quadros diretivos.

\section{CUSTOS}

Em primeiro lugar, necessitam as repartições de áreas verdes ter claro quais valores devem hoje ser administrados e gerenciados pelo serviço público urbano. Tendo como exemplo Hamburgo isto fica claro:

\section{Exemplo 1: árvores de rua}

Custo/ valor de plantação 500,- Euros

(inclusive substrato, tutores, etc.)

Em 245.000 árvores em Hamburgo

Valor efetivo de uma árvore monta, porém, em media, cerca de Isto significa em Hamburgo um valor total de todas as árvores de rua de mais quantificáveis custos de manutenção anuais de $2 \%$ do valor total correspondentes
122.500.000,- Euros

5.000,- Euros

1.225.000.000,- Euros

2.450.000,- Euros

24.500.000,- Euros

\section{Exemplo 2: Parque, aqui: Parque Público de Hamburgo (Stadtpark)}
148 ha $\times 25,-$ Euros $/ \mathrm{m}^{2}$ custo de implantação
$37.000 .000,-$ Euros
$740.000,-$ Euros
mais custos de manutenção $2 \% / a n o$
0,5 Euros $/ \mathrm{m}^{2} /$ ano
correspondente

\section{0,5 Euros $/ \mathrm{m}^{2} /$ ano}

a amortização do Parque Publico (Stadtpark) monta em um prazo de 80 anos anuais, isto é, precisa-se anualmente, para o Parque Publico

para reinvestimento e manutenção

cerca de 1.200.000,00 Euros disponíveis para assegurar uma boa condição sustentável. 
Os valores para o cuidado e manutenção anual das árvores de rua e dos parques naturalmente não se encontram disponíveis na medida apresentada. Com a constante escassez de meios apesar de uma surpreendente qualidade a ser conseguida procura-se um alto "Know-how" técnico e cientifico, bem como um gerenciamento ótimo.

Com a introdução do principio de custo-benefício em muitas repartições de áreas verdes conseguiu-se uma transparência de custos tornada pública onde a otimização dos benefícios é importante e possível e quais os benefícios são mais propícios de se apresentar, se por um órgão diretor, se por empresas privadas. Estas possibilidades de comparação de custos e as decisões "make-or-buy" conseguidas para isso, têm nos últimos anos reduzido os orçamentos das repartições de áreas verdes não agravando com isso a qualidade dos parques e áreas verdes como, propriamente, poder-se-ia esperar.

\section{ORIENTAÇÃO DA CLIENTELA}

Em muitas repartições de áreas verdes foram introduzidas análises de mercado sobre os anseios da população no que se refere à oferta de verde público, em parques, em áreas de recreação. Com diversos métodos foi pesquisada a evolução dos comportamentos no tempo livre e nos desejos de lazer da população e colocadas as correspondentes medidas para reforma e modernização dos parques na cidade. Isto ficou claro especialmente na mudança da oferta para jovens no campo dos esportes em moda ou tendo em vista a modificação da estrutura etária nas cidades em favor dos veteranos na oferta e conformação dos parques. Quase nunca um planejamento para a construção de novas áreas verdes ou sua reforma acontece sem a participação dos cidadãos. Em Hamburgo, por exemplo, com o conceito de "cidade como espaço de recreação" há mais de dez anos a participação de crianças e jovens é obrigatória. Na reforma dos parques existentes hoje se pesquisa visitantes e não visitantes por diferentes métodos sobre seus desejos e motivações de visita para verificar os fundamentos para o posterior desenvolvimento de ofertas e equipamentos no parque.

\section{MÉTODOS MODERNOS DE GERENCIAMENTO}

Evidentemente muitas repartições de áreas verdes introduziram modernos instrumentos de gerenciamento: junto com a Avaliação de Custo-Beneficio foi naturalmente inserido um meio de controle e de relatório para uma eficiente condução. Bases para esta condução são hoje os Sistemas Digitais Geográficos de Informação.

Em Hamburgo baseado em Espécies de Verde e Tipos de Verde (Anexo 1) efetuase um sistemático registro da capacidade dos parques pelo conhecido NetGris, o sistema 
geográfico de informações sustentado pela rede. Baseando-se nisso pode-se dividir os encargos dos colaboradores das colunas de manutenção ou das firmas e atingir os custos para todos os objetivos no âmbito dos parques.

Evidentemente serão utilizados hoje os meios modernos tais como a Internet para a própria publicidade. Em Hamburgo foi desenvolvido para o verde público há quatro anos um Conceito de Imagem e Marketing e tem sido conseqüentemente ampliado desde então. A "Homepage" www.stadtgruen.hamburg.de apresenta a administração de áreas verdes de Hamburgo com suas tarefas e da dicas e informações sobre diversos temas.

Por isso a administração de áreas verdes de Hamburgo em sua estrutura orienta-se segundo as novas exigências: nas repartições centrais se localiza a tarefa do gerenciamento total dos recursos para investimentos e disponibilização dos meios para o cuidado e manutenção das áreas verdes e áreas livres; aqui são coordenadas as contribuições do planejamento verde para o desenvolvimento urbano; são formuladas as premissas para o cuidado e desenvolvimento dos parques; as premissas de suporte para o desenvolvimento da regular distribuição de áreas e a disponibilidade à população de suficientes áreas verdes e áreas livres; são estabelecidas as premissas técnico-construtivas para a execução das obras possíveis. Nas sete administrações regionais são aplicadas as metas e premissas correspondentes. 